\title{
Plasma fibrinogen of black South Africans: the BRISK study
}

\author{
HH Vorster ${ }^{1, *}$, JC Jerling ${ }^{1}$, K Steyn ${ }^{2}$, CJ Badenhorst ${ }^{2}$, W Slazus ${ }^{3}$, CS Venter ${ }^{1}$, PL Jooste ${ }^{4}$ \\ and LT Bourne ${ }^{2}$ \\ ${ }^{1}$ Department of Nutrition, PU for CHE, Potchefstroom, 2520, South Africa: ${ }^{2}$ Division for Chronic \\ Diseases of Lifestyle, MRC, Tygerberg, 7505, South Africa: ${ }^{3}$ Department of Haematology and \\ Pathology, Faculty of Medicine, US, Stellenbosch, 7600, South Africa: ${ }^{4}$ National Research \\ Programme for Nutrition Intervention, MRC, Tygerberg, 7505, South Africa
}

\section{Submitted 26 February 1998: Accepted 28 April 1998}

\begin{abstract}
Objective: To describe the distribution of plasma fibrinogen and relationships with other risk factors for coronary heart disease (CHD) and stroke in the black population of the Cape Peninsula.

Design: A cross-sectional survey of a stratified proportional sample of randomly selected black men and women.

Setting: Households in Gugulethu, Langa, Nyanga, New Crossroads, KTC, Old Crossroads and Khayelitsha in the Cape Peninsula, South Africa.

Subjects: One subject per household (352 men and 447 women), aged 15-64 years, voluntarily participated. Visitors, pregnant, lactating, ill, mentally retarded and intoxicated subjects were excluded.

Results: Mean fibrinogen (thrombin time coagulation method) of men and women were higher than published data for Europeans but slightly lower than values of black Americans. Women aged 45-54 years had the highest level $\left(3.13 \pm 0.89 \mathrm{gl}^{-1}\right)$ and men aged $15-24$ years had the lowest $\left(2.13 \pm 0.88 \mathrm{gl}^{-1}\right)$. Fifteen per cent of the men and $12 \%$ of the women had a level greater than 1 standard deviation of the mean for their age group. Univariate and multivariate analyses revealed significant $(P<0.05)$ positive correlations of fibrinogen with smoking habit, age, body mass index (BMI), total and low-density lipoprotein (LDL) cholesterol, triglycerides, blood pressure and white blood cell count, and significant negative correlations with high-density lipoprotein (HDL) cholesterol, gamma glutamyl transferase (GGT), serum iron and ferritin. The correlations with BMI, serum lipoproteins, iron, ferritin, and GGT suggest that nutritional status and therefore diet influences plasma fibrinogen.

Conclusion: Relatively high fibrinogen levels, tending to cluster with other, including diet-related, risk factors for CHD and stroke, were observed in black South Africans. It is suggested that fibrinogen may contribute to the high stroke incidence of this population group.
\end{abstract}

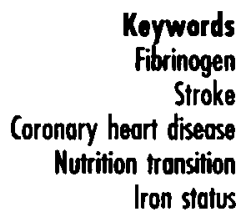

In a recent editorial ${ }^{1}$, Steyn pointed out that chronic diseases of life-style and their risk factors have a major impact on disease patterns in South Africa. It is suspected that as diseases of poverty are controlled in developing sectors, chronic diseases of life-style will become more common. This phenomenon, the epidemiological transition, is characterized by a nutrition transition during which traditional low-fat high-fibre diets are changing to more Westernized high-fat, low-fibre diets ${ }^{2}$. Raised plasma fibrinogen has now been identified as a major, independent risk factor for coronary heart disease (CHD) in prospective epidemiological surveys ${ }^{3-8}$. Three prospective studies also identified fibrinogen as a major risk factor for stroke ${ }^{3,5,9}$. Cross-sectional studies ${ }^{10-12}$ have shown that fibrinogen is associated with most other risk factors for
CHD and stroke, while clinical and basic research ${ }^{13}$ have illuminated many possible mechanisms by which fibrinogen contributes to the atherosclerotic and thrombotic processes. Fibrinogen levels are genetically determined $^{14}$, but can be influenced by a variety of environmental and life-style factors ${ }^{15}$. It is suspected that race may influence levels, with black people having higher and Japanese lower levels than white people ${ }^{16,17}$. There is very little information available on fibrinogen levels of black South Africans. One study ${ }^{17}$, which examined fibrinogen in small groups of South Africans, indicated that levels were significantly higher in an urban black group compared to the rural black and white controls, indicating that life-style factors such as diet may play a role. In the present study, plasma fibrinogen levels and its relationship to other risk 
factors of CHD and stroke are described for randomly selected men $(n=352)$ and women $(n=447)$ aged $15-$ 64 years from the black population of the Cape Peninsula. The study formed part of the 1990 BRISK study (Coronary Heart Disease Risk Factor Study in the African Population of the Cape Peninsula).

\section{Methods and materials}

\section{Selection of participating subjects}

The sampling procedures and data collection methodology of the BRISK study have been described in detail elsewhere $^{18,19}$. Briefly, a multistage stratified proportional random sample of black men and women aged 15-64 years was drawn from residents (including squatters) in Gugulethu, Langa, Nyanga, New Crossroads, KTC, Old Crossroads and Khayelitsha. One subject per household voluntarily participated. A household was defined as a group of people who cook and eat together. Pregnant and lactating mothers, mentally retarded and bedridden people, persons under treatment or recovering from major illness, temporary visitors and intoxicated persons were excluded from the study.

\section{Data collection}

Trained field workers employing standardized interviewing procedures had personal interviews with subjects. Risk factor and dietary intake questionnaires were completed. Information on aspects of urbanization, socioeconomic background, family history of CHD and related diseases, smoking habits, physical activity patterns and items on health actions were collected. Height was measured to the nearest $0.5 \mathrm{~cm}$, using a metal measuring tape placed against a wall and a flat headboard at right angles to the wall. Weight was measured with a calibrated quality bathroom scale. Blood pressure was recorded after subjects were seated for at least $5 \mathrm{~min}$, using a mercury manometer. Cuffs were adapted according to mid-upper arm circumference. The first and fifth Korotkoff sounds were recorded as systolic and diastolic pressures, respectively.

\section{Blood sampling}

Trained registered professional nurses drew a nonfasting venous blood sample, with or without minimal stasis, from the anterior cubital vein of participating subjects. Blood samples were taken from 18:00 to 22:00 on week days and from 10:00 to 15:00 on weekend days. A sterile, disposable 23 gauge butterfly system combined with two $10 \mathrm{ml}$ and one $20 \mathrm{ml}$ syringes were used. One $10 \mathrm{ml}$ syringe contained $1 \mathrm{ml} 3.8 \mathrm{mmol} \mathrm{l}^{-1}$ trisodium citrate solution and exactly $9.0 \mathrm{ml}$ blood was drawn $(1: 9 \mathrm{v} / \mathrm{v})$ for preparation of citrated plasma for the fibrinogen and factor VI coagulant activity measurements. Blood from the other syringes were used for the preparation of ethylene diaminetetraacetic acid (EDTA) blood for full and differential blood counts, EDTA plasma for lipids and lipoproteins, and serum for iron status measurements. All samples (except the aliquot for factor VIIc analysis) were kept on ice at $4^{\circ} \mathrm{C}$ until centrifugation within $6 \mathrm{~h}$. Samples were analysed within $24 \mathrm{~h}$.

\section{Biochemical analyses}

Fibrinogen was measured with the thrombin time coagulation method using the Ortho quantitative fibrinogen assay (Ortho, Ravitan, New York). A pooled normal plasma (Calibration plasma IL, Milan) was assayed with each batch as a quality control procedure. Factor VII coagulant activity was measured according to the method described by Osterud ${ }^{20}$ on an ACL coagulometer (IL, Milan, Italy) using Reference 100 (IMMUNO) as a standard and human brain thromboplastin. A pooled normal plasma (Calibration plasma IL, Milan) was assayed on each rotor as a quality control procedure. The coefficient of variation (CV) of a pooled normal plasma was $<5 \%$ for fibrinogen and factor VIIc measurements. Total and high-density lipoprotein (HDL) cholesterol were determined enzymatically on a Gilford autoanalyser with reagents from Boehringer Mannheim (BM) (Mannheim, Germany). Low-density lipoprotein (LDL) cholesterol was calculated using the Friedewald equation. The $1 \%$ of subjects who had triglyceride levels $>4.5 \mathrm{mmoll}^{-1}$ were excluded. For HDL cholesterol measurements, apo-B containing lipoproteins were precipitated with manganese heparin. Triglycerides were measured with an enzymaticcolorimetric method from BM. Serum ferritin concentration was determined by radioimmunoassay (Diagnostic Products Corporation, Los Angeles, USA), and radioactivity in a Crystal Multidetector Gamma counter (Packard, USA). Serum iron and transferrin concentrations were estimated with a Technicon RA-1000 automated system using BM kits. Serum total ironbinding capacity (TIBC) was determined using a BM magnesium carbonate precipitator kit. Transferrin saturation was calculated by expressing total serum iron as a percentage of TIBC. Appropriate internal and external control and standard serum and plasmas were used in all instances for quality control.

\section{Statistical analyses}

The Complete Statistical System package ${ }^{21}$ was used to calculate means, standard deviations, 5th and 95th percentiles of the fibrinogen distribution for men and women in the age groups 15-24, 25-34, 35-44, 45-54 and 55-64 years. The fibrinogen levels of groups (based on age, sex, smoking habit and body mass index, BMI) were compared using an analysis of variance, followed by the Tukey Honest Significant Difference (HSD) tests. The relationship of fibrinogen 
with other measured variables (except dietary intake data) was examined using univariate (Pearson correlations) and multiple regression models. The latter was done with an all subsets regression procedure, using the SAS system. Cut-off points for risk factor levels are discussed and motivated in the results section.

\section{Etbical considerations}

Consultations with the community, as well as feedback of results to the community have been described in detail $^{18}$. Ethical approval for the study was obtained from the Ethics Committees of the SA Medical Research Council and the University of Cape Town. Written informed consent was obtained from each participant prior to the study.

\section{Results}

\section{Mean fibrinogen levels}

The mean fibrinogen levels with standard deviations and $95 \%$ confidence intervals of men and women of the different age groups are given in Table 1. Levels increased with age up to 54 years but were slightly but not significantly, lower in the 55-64 year old groups than at age 45-54 years.

Table 1 also gives the percentage of subjects in each age group ( $15 \%$ of all men and $12 \%$ of all women) who had a fibrinogen level of 1 standard deviation above the mean for the group. The Northwick Park Heart Study ${ }^{4}$ showed that this level was associated with an $84 \%$ increase in CHD risk. The highest prevalence occurred in the 55-64 year old men and women.

\section{Effect of smoking}

The detrimental effect of smoking on fibrinogen has been reported in all the major epidemiological surveys $^{3-9}$. The effect of smoking in the BRISK population is illustrated in Table 1 . The higher levels in smokers were not significantly different from those in former and nonsmokers, probably because of the large variation of fibrinogen and confounding factors in this population. Both the univariate analysis (Pearson correlation coefficients in Table 2) and multivariable analyses (Table 3), indicated that the packet years of smoking correlated significantly with fibrinogen level in the men.

\section{Effect of BMI}

In Table 1 the mean fibrinogen levels of men and women, grouped according to BMI, regardless of age, are compared. In the same BMI range, women had higher mean fibrinogen levels than men. Steyn et al. ${ }^{19}$ showed that $7.9 \%$ of the men and $44.4 \%$ of the women aged 15-64 years in this population, had a BMI of $>30 \mathrm{~kg} \mathrm{~m}^{-2}$. Of the 45-54 year old women, $59.4 \%$ could be classified as obese. This was also the group who had the highest mean fibrinogen level of $3.13 \pm 0.89 \mathrm{gl}^{-1}$. Table 1 indicates further that the lean men (BMI $<19-25 \mathrm{~kg} \mathrm{~m}^{-2}$ ) had the lowest fibrinogen, but that the underweight women (BMI $<19 \mathrm{~kg} \mathrm{~m}^{-2}$ ) had a higher fibrinogen than women with normal weight (BMI of $19-25 \mathrm{~kg} \mathrm{~m}^{-2}$ ). A multivariate analysis (two-way analysis of variance) with fibrinogen as the dependent variable showed a highly significant interaction of gender $(P=0.0001)$ and BMI $(P=0.001)$ with fibrinogen. The gender by BMI interaction was not significant $(P=0.65)$.

Table 1 Distribution of plasma fibrinogen levels of men and women in different age, smoking and BMI groups (Cl $95 \%$ )

\begin{tabular}{|c|c|c|c|c|c|c|c|c|c|c|c|c|}
\hline \multirow[b]{3}{*}{ Variable } & \multicolumn{12}{|c|}{ Fibrinogen } \\
\hline & \multicolumn{6}{|c|}{ Men } & \multicolumn{6}{|c|}{ Women } \\
\hline & $n$ & $x$ & $\mathrm{SD}$ & $\mathrm{Cl}$ & 5 th* & 95 th $^{*}$ & $n$ & $x$ & SD & $\mathrm{Cl}$ & 5 th & 95th \\
\hline $\begin{array}{l}\text { Age (years) } \\
15-24 \\
25-34 \\
35-44 \\
45-54 \\
55-64\end{array}$ & $\begin{array}{r}120 \\
84 \\
68 \\
45 \\
35\end{array}$ & $\begin{array}{l}2.31 \\
2.42 \\
2.58 \\
2.72 \\
2.63\end{array}$ & $\begin{array}{l}0.88 \\
0.88 \\
1.03 \\
1.04 \\
0.59\end{array}$ & $\begin{array}{l}2.15 ; 2.47 \\
2.23 ; 2.61 \\
2.34 ; 2.83 \\
2.42 ; 3.02 \\
2.43 ; 2.83\end{array}$ & $\begin{array}{l}1.30 \\
1.45 \\
1.50 \\
1.30 \\
1.70\end{array}$ & $\begin{array}{l}3.73 \\
4.43 \\
4.00 \\
4.80 \\
3.70\end{array}$ & $\begin{array}{r}151 \\
116 \\
85 \\
54 \\
41\end{array}$ & $\begin{array}{l}2.62 \\
2.78 \\
2.70 \\
3.13 \\
3.07\end{array}$ & $\begin{array}{l}0.88 \\
0.77 \\
0.82 \\
0.89 \\
0.99\end{array}$ & $\begin{array}{l}2.48 ; 2.76 \\
2.64 ; 2.92 \\
2.53 ; 2.87 \\
2.89 ; 3.37 \\
2.77 ; 3.37\end{array}$ & $\begin{array}{l}1.50 \\
1.85 \\
1.55 \\
1.75 \\
1.60\end{array}$ & $\begin{array}{l}4.20 \\
4.10 \\
4.10 \\
5.40 \\
4.80\end{array}$ \\
\hline $\begin{array}{l}\text { Smoking } \\
\text { Current } \\
\text { Former } \\
\text { Never }\end{array}$ & $\begin{array}{l}\% \\
50 \\
12 \\
38\end{array}$ & $\begin{array}{l}2.55 \\
2.35 \\
2.40\end{array}$ & $\begin{array}{l}1.07 \\
0.58 \\
0.75\end{array}$ & & & & $\begin{array}{r}\% \\
7 \\
2 \\
91\end{array}$ & $\begin{array}{l}2.84 \\
3.43 \\
2.76\end{array}$ & $\begin{array}{l}0.90 \\
1.27 \\
0.86\end{array}$ & & & \\
\hline $\begin{array}{l}B M I\left(\mathrm{~kg} \mathrm{~m}^{-2}\right) \\
<19 \\
\geq 19<25 \\
\geq 25<30 \\
>30\end{array}$ & $\begin{array}{r}\% \\
9 \\
57 \\
27 \\
7\end{array}$ & $\begin{array}{l}2.39 \\
2.39 \\
2.56 \\
2.83\end{array}$ & $\begin{array}{l}1.09 \\
0.84 \\
1.00 \\
0.84\end{array}$ & & & & $\begin{array}{r}\% \\
4 \\
26 \\
36 \\
34\end{array}$ & $\begin{array}{l}2.90 \\
2.57^{1} \\
2.78 \\
2.92^{1}\end{array}$ & $\begin{array}{l}1.03 \\
0.85 \\
0.86 \\
0.85\end{array}$ & & & \\
\hline
\end{tabular}

* 5 th and 95 th estimated percentile.

$\%$, percentage of total subjects (men, women).

${ }^{1}$ Means with the same symbol differ significantly (Tukey HSD test; age adjusted; $P<0.01$ ). 
Table 2 Pearson correlation coefficients $(r)$ of fibrinogen with risk factors for CHD and stroke

\begin{tabular}{lccc}
\hline Variable & Total group & Men & Women \\
\hline Serum iron & $-0.21^{* * *}$ & $-0.19^{* *}$ & $-0.18^{* *}$ \\
Gamma glutamyl transferase & $-0.20^{* * *}$ & $-0.18^{* * *}$ & $-0.20^{* * *}$ \\
Factor Vilc & $0.20^{* * *}$ & $0.18^{* * *}$ & $0.21^{* * *}$ \\
Packet years of smoking & $0.19^{*}$ & $0.20^{*}$ & $-0.14 \mathrm{NS}$ \\
Body mass index & $0.18^{* * *}$ & $0.15^{* *}$ & $0.12^{* *}$ \\
Age & $0.18^{* * *}$ & $0.18^{* * *}$ & $0.19^{* * *}$ \\
Triglycerides & $0.18^{* * *}$ & $0.30^{* * *}$ & $0.05 \mathrm{NS}$ \\
Total cholesterol & $0.16^{* * *}$ & $0.20^{* *}$ & $0.11^{*}$ \\
White blood cell count & $0.13^{* *}$ & $0.13^{*}$ & $0.15^{* *}$ \\
LDL cholesterol & $0.10^{* *}$ & $0.04 \mathrm{NS}$ & $0.09 \mathrm{NS}$ \\
HDL cholesterol & $-0.10^{*}$ & $-0.16^{* *}$ & $-0.02 \mathrm{NS}$ \\
Blood pressure & & & \\
systolic & $0.08^{*}$ & $0.05 \mathrm{NS}$ & $0.12^{*}$ \\
diastolic & $0.06 \mathrm{NS}$ & $0.00 \mathrm{NS}$ & $0.10^{*}$ \\
\hline
\end{tabular}

NS, not significant, $P>0.05 ;{ }^{*} P<0.05 ;{ }^{* *} P<0.001 ;{ }^{* *} P<0.0001$.

\section{Correlations with other $\mathrm{CHD}$ risk factors}

The significant positive correlations of fibrinogen with age, BMI, amount of cigarettes smoked, triglycerides, total and LDL cholesterol, and the negative correlations with HDL cholesterol and serum gamma glutamyl transferase (GGT) levels, which was used as proxy measure for ethanol consumption, given in Table 2, were also described in a number of cross-sectional surveys in Europe and the USA ${ }^{10-12,22,23}$. The magnitude of these correlations was low but of the same order as most other studies ${ }^{12}$, but slightly higher than those found in the German study ${ }^{23}$.

A novel finding is the highly significant negative correlation of fibrinogen with serum iron in the BRISK population. The mean fibrinogen level of subjects with a serum iron of $<50 \mu \mathrm{g} \mathrm{dl}^{-1}$ was $2.91 \mathrm{gl}^{-1}$, for subjects with serum iron of $50-200 \mu \mathrm{gl}^{-1}$ (normal range) it was $2.61 \mathrm{gl}^{-1}$ and for those with iron levels $>200 \mu \mathrm{gl}^{-1}$, $2.07 \mathrm{gl}^{-1}$. These means differed significantly $(P<0.01)$.

Table 3 illustrates the results of the multivariate analyses. An all subsets regression procedure was used to select a model in which all possible equations containing one, two, three or more variables were examined. In both the men and women, as well as the total group, the model with eight variables gave the maximum multiple correlation (largest $R^{2}$ and $R^{2}$ adjusted for the number of variables) for the smallest $C(p)$ criterium (Table 3).

Table 3 also shows the significance of the relationships of these variables with fibrinogen for the total group. In men, the variables with a significant relationship were HDL, factor VII, serum iron, packet years of smoking and GGT, which also showed a significant correlation in univariate analyses (Table 2). In women, a similar situation was observed, with white blood cell count, percentage HDL, factor VII and GGT showing significant relationships with fibrinogen. The multiple regression analyses further indicated that the model with the eight selected variables, could explain $23.2 \%$ of the variation in fibrinogen in men, $17.2 \%$ in women (results not shown in tables) and $17.0 \%$ in the total group.

\section{Clustering of risk factors}

The percentage of men and women who had none, one or more of the accepted risk factors for $\mathrm{CHD}$, all ages combined, are shown in Table 4. The risk factors considered were total cholesterol, with the cut-off point of $5.7 \mathrm{mmoll}^{-124}$, systolic blood pressure $>140 \mathrm{mmHg}$, smoking (yes or no), BMI $\left(>30 \mathrm{~kg} \mathrm{~m}^{-2}\right.$ ) and fibrinogen. Two cut-off points of fibrinogen, 3.0 and $3.5 \mathrm{gl}^{-1}$ were considered. Ernst ${ }^{15}$ reviewed the literature and concluded

Table 3 Regression models for fibrinogen as dependent variable ${ }^{1}$

\begin{tabular}{lcccccl}
\hline $\begin{array}{l}\text { Variable } \\
\text { intercept }\end{array}$ & $\begin{array}{c}\text { Number } \\
\text { in model }\end{array}$ & $P$ & $R^{2}$ & Adjusted $R^{2}$ & $C(p)$ & \\
\hline GGT & 1 & 0.0001 & 0.044 & 0.042 & 45.7 & GGT \\
SI & 2 & 0.0001 & 0.087 & 0.083 & 28.8 & SI, GGT \\
FVII & 3 & 0.0001 & 0.11 & 0.10 & 20.7 & FVII, SI, GGT \\
\%HDL & 4 & 0.002 & 0.13 & 0.12 & 12.9 & HDL, FVII, SI, GGT \\
WBC & 5 & 0.001 & 0.15 & 0.14 & 8.6 & WBC, HDL, FVII, SI, GGT \\
Fer & 6 & 0.80 & 0.16 & 0.14 & 6.2 & WBC, HDL, FVII, Fer, SI, GGT \\
TG & 7 & 0.39 & 0.16 & 0.15 & 5.6 & WBC, HDL, TG, FVII, Fer, SI, GGT \\
TC & 8 & 0.16 & 0.17 & 0.15 & 4.7 & WBC, TC, \%HDL, TG, FVII, Fer, SI, GGT \\
PY & 9 & & 0.17 & 0.15 & 4.9 & WBC, TC, \%HDL, TG, FVII, Fer, SI, PY, GGT \\
BMI & 10 & & 0.18 & 0.16 & 5.0 & WBC, TC, \%HDL, TG, FVII, BMI, Fer, SI, PY, GGT \\
\hline
\end{tabular}

'All subsets procedure, total group, using the SAS system.

SI, serum iron; FVII, clotting tactor VIl; WBC, white blood cell count; Fer, ferritin; TG, triglyceride; TC, total cholesterol; PY, packet years of smoking 
that 'a level in excess of $3.5 \mathrm{gl}^{-1}$ is a powerful, independent primary risk factor for brain and/or heart infarction'. We therefore considered this level, as well as the level of $3.0 \mathrm{gl}^{-1}$, because the Clauss method used to determine fibrinogen in the present study tends to give lower values than other methods ${ }^{25-27}$. (Diabetes mellitus was not included as a risk factor.) Diabetes was not diagnosed in this study, and only 21 of the subjects of whom fibrinogen was measured, reported that they had diabetes.

Table 4 shows that without fibrinogen in the model, $40.8 \%$ of the men and $53.5 \%$ of the women had no CHD risk factors. Inclusion of fibrinogen in the model at a cut-off point of $3.0 \mathrm{gl}^{-1}$ decreased the percentage of men and women with at most one risk factor with 13 and $15.8 \%$, respectively, and increased the percentage with two or more risk factors accordingly - an approximate threefold increase in the two, three and four risk factor categories. The respective percentage shifts when the cut-off point for fibrinogen was $3.5 \mathrm{~g} \mathrm{l}^{-1}$, were 2.7 for men and 7.4 for women. There was therefore a tendency for high fibrinogen levels to occur in subjects who also had other risk factors.

\section{Discussion}

\section{Mean fibrinogen levels}

In comparison with values reported for Europeans in studies where the thrombin time coagulation method for fibrinogen was also used, the fibrinogen levels are higher in this black population. For example, in the Scottish Heart Health study ${ }^{10}$ the men and women in the 45-49 age group, had mean levels of 2.27 ( \pm 0.66 ) and $2.30( \pm 0.62) \mathrm{gl}^{-1}$, which are 0.45 and $0.83 \mathrm{gl}^{-1}$ lower than that of the comparable age group in our study. Comparison of these mean levels with the confidence intervals observed in the BRISK study indicate that they are outside the BRISK intervals. For example, consider the men in the 45-49 age group of the Scottish study with a mean level of $2.27 \mathrm{gl}^{-1}$. In the BRISK men of this age group the $95 \%$ confidence interval is from 2.42 to $3.02 \mathrm{gl}^{-1}(2.72 \pm 1.96 \times 1.04 /$ $(45)^{1 / 2}$ ), well beyond that of the Scottish study. The mean levels in each age group, except for the 55-64 year old men, were consistently higher (1.06$0.41 \mathrm{gl}^{-1}$ ) in the BRISK population than levels observed in Germans participating in the Prospective Cardiovascular Münster (PROCAM) study ${ }^{7}$. However, in comparison with values reported for black Americans in the Atherosclerosis Risk in Communities (ARIC) study $^{8-11}$, the BRISK population have mean levels of $0.10,0.26,0.30$ and $0.54 \mathrm{gl}^{-1}$ lower than the respective groups of 45-54 and 55-64 year old black American men and women. The 45-50 year old BRISK men and women had slightly higher fibrinogen levels reported for a smaller group of rural Vendas ${ }^{17}$ of 2.15 and $2.40 \mathrm{gl}^{-1}$, but similar values $\left(2.8 \mathrm{gl}^{-1}\right)$ reported for semi-Westernized Tswana men and women ${ }^{17}$. These levels of the Tswana men and women were significantly higher than levels of white control subjects of the same age and living in the same area. The ARIC study also reported higher levels of fibrinogen in all age groups for black compared with white people ${ }^{8,11}$. In agreement with a large number of studies, the women of the BRISK population had higher mean levels, although not statistically significant, than men in all age groups.

A French study ${ }^{10}$ established reference limits for fibrinogen in 1008 healthy fasting subjects with 'normal' body weight, who smoked less than five cigarettes per day, took less than $22 \mathrm{~g}$ alcohol daily, and who did not use drugs and/or oral contraceptives. Comparing the BRISK data with these reference limits, as well as with the PROCAM $^{7}$ results, the values in both sexes in each age group for the 5 th percentile were consistently lower and for the 95th percentile consistently higher in the BRISK population.

Table 4 Clustering of CHD risk factors ${ }^{1}$ in the study population

\begin{tabular}{|c|c|c|c|c|c|c|}
\hline \multirow{4}{*}{$\begin{array}{l}\text { Number of risk } \\
\text { factors present }\end{array}$} & \multicolumn{5}{|c|}{ Percentage of subjects } & \\
\hline & \multicolumn{3}{|c|}{$\operatorname{Men}(n=346)^{2}$} & \multicolumn{3}{|c|}{ Women $(n=432)^{2}$} \\
\hline & \multirow{2}{*}{$\begin{array}{l}\text { Without } \\
\text { fibrinogen }\end{array}$} & \multicolumn{2}{|c|}{ With fibrinogen } & \multirow[b]{2}{*}{ Without fibrinogen } & \multicolumn{2}{|c|}{ With fibrinogen } \\
\hline & & $\geq 3.00 \mathrm{gl}^{-1}$ & $\geq 3.50 \mathrm{gl}^{-1}$ & & $\geq 3.00 \mathrm{gl}^{-1}$ & $\geq 3.50 \mathrm{gl}^{-1}$ \\
\hline 0 & 40.8 & 33.8 & 38.8 & 53.5 & 39.6 & 46.1 \\
\hline 1 & 52.0 & 46.0 & 46.0 & 33.6 & 31.7 & 34.0 \\
\hline 2 & 6.0 & 17.1 & 12.4 & 10.9 & 21.8 & 15.5 \\
\hline 3 & 0.9 & 2.3 & 2.3 & 1.6 & 5.8 & 3.5 \\
\hline 4 & 0.3 & 0.9 & 0.6 & 0.4 & 0.9 & 0.7 \\
\hline 5 & & 0 & 0 & & 0.2 & 0.2 \\
\hline
\end{tabular}

\footnotetext{
${ }^{1}$ Cut-off points for risk factors were:

total cholesterol: $5.7 \mathrm{mmoll}^{-1}$

blood pressure: $140 \mathrm{mmHg}$ (systolic)

smoking: yes or no

body mass index: $30 \mathrm{~kg} \mathrm{~m}^{-2}$

fibrinogen: $3.00 \mathrm{gl}^{-1}$ and $3.50 \mathrm{gl}^{-1}$

${ }^{2}$ Number of subjects for whom all information was complete.
} 
The reason for the higher levels observed in these black people is not known. Blood fibrinogen concentration is largely genetically determined, but may be influenced by a variety of environmental or life-style factors $^{13,15}$. Published differences in fibrinogen level between rural and semi-Westernized black people ${ }^{17}$ suggest that the higher levels in black people may be attributed to environmental factors associated with acculturation, such as diet. In the BRISK population, no association could be found between fibrinogen level and reported number of years that subjects had lived in a city environment. However, the associations of fibrinogen with other diet-related CHD risk factors (positive with BMI, triglycerides, total and LDL cholesterol and blood pressure, and negative with HDL cholesterol, serum iron, ferritin and GGT) suggest that nutritional status and therefore diet may be responsible.

The relatively high and significant negative correlation of fibrinogen with serum iron observed, suggest a common hepatic involvement in low serum iron and high fibrinogen levels and vice versa. This aspect should be examined in more detail in clinical studies. The possibility that high serum iron levels and low fibrinogen are consequences of hepatic disease, cannot be excluded. Haemosiderosis, a condition related to iron overload is well documented among black South Africans. A high prevalence of iron overload was noted among males aged 45-64 years in the BRISK population (unpublished results).

The consistently higher levels of fibrinogen in all age groups of women compared to men, reported in a number of other studies ${ }^{4-12}$ were also found in the present study. Differences were, however, not statistically significant. It is possible that in addition to hormonal differences and the influence of oral contraceptives and the menopause ${ }^{28}$ the higher incidence of obesity in the women of this study population could have contributed to their higher fibrinogen levels.

The study further showed that $15 \%$ of all men and $12 \%$ of all women had a fibrinogen level of 1 standard deviation above the mean - a level associated with a marked increase in CHD risk $^{4}$. Furthermore, the association and clustering of fibrinogen with other risk factors suggest an interrelated aetiology of these risk variables. The practical implication is that with correction of life-style and environmental factors, a number of risk factors - possibly also fibrinogen - will be addressed simultaneously.

\section{Fibrinogen as a risk factor for CHD and stroke}

Despite the prevalence of a number of CHD risk factors in this population ${ }^{19}$ and the potential contribution of fibrinogen to CHD risk, mortality rates from $\mathrm{CHD}$ in South African black people are still very low compared with other population groups ${ }^{29}$. In contrast to black Americans who already have high rates ${ }^{30}$ it is clear that different risk profiles must be present in the two groups. The black people in the Cape Peninsula have markedly lower LDL cholesterol levels and lower rates of hypertension than American black people ${ }^{19}$. The higher HDL cholesterol level of South African black people has been identified as a major possible protective factor ${ }^{19}$. Of the BRISK population, $96 \%$ of all subjects had a protective HDL total cholesterol ratio of $>20 \%{ }^{19}$ with mean levels of all age groups $>30 \%$ (data not shown here). Vermaak et al. ${ }^{31}$ have shown that compared with white control subjects exposed to the same diet and environment, a group of black South Africans had substantially lower levels of homocysteine and coagulation factor VII, possibly protecting them. against $\mathrm{CHD}$. Black people also have higher fibrinolytic activity $^{32}$ and lower plasminogen activator inhibitor 1 levels ${ }^{33}$, conferring more protection against CHD. These factors (except for factor VII coagulant activities which were low to normal) were not measured in the BRISK study.

It is possible that high fibrinogen levels contribute to the excessive mortality rate of stroke in South African $^{34,35}$ and American ${ }^{36}$ black people. The first convincing evidence that increased fibrinogen is a risk factor for stroke came from the Göteborg prospective study ${ }^{2}$ in which a randomized group of 792 Swedish men born in 1913, were followed for 13.5 years (from 1967 to 1980). In this study 92 men suffered a myocardial infarction and 37 a stroke incident (only primary incidents were recorded). A fibrinogen level $>3.5 \mathrm{gl}^{-1}$ emerged as a stronger risk factor for stroke than hypertension. A subgroup of the men were followed for another 7.5 years ( 21 years in total) in a follow-up study ${ }^{9}$ and multivariate analyses again identified fibrinogen and hypertension as the major risk factors for stroke.

The greater incidence of stroke among black people has often been attributed to a high prevalence of hypertension and diabetes mellitus among black people. Kittner et al. ${ }^{37}$ analysed findings of the 10year follow-up of the First National Health and Nutrition Survey in the USA, and showed a higher estimated incidence of stroke in black people after adjustment for age, hypertension and diabetes mellitus. Among these subjects, the relative risk of stroke associated with hypertension and diabetes were unrelated to race. This suggests that another factor predisposes to strokes. The Göteborg prospective study results raises the possibility that a high fibrinogen level could be the risk factor that contributes to the unexpected high stroke rate.

Circumstantial evidence that fibrinogen may be responsible, comes from a clinical study ${ }^{38}$ which found higher D-dimer levels (the degradation product of fibrin) more frequently in black than in white stroke patients. At least two studies ${ }^{39,40}$ have shown that low 
educational achievement and occupational structure are associated with the excess stroke mortality rates within USA Afro-American communities, and it has been shown that low social class ${ }^{41}$ and job stress ${ }^{42}$ are associated with high fibrinogen levels.

It therefore seems possible that the relatively high fibrinogen levels observed in the BRISK population may contribute, or even be a major causative factor of the excess mortality rates from stroke in black people. ${ }^{34,35}$

The potentially changeable life-style factors which may lower fibrinogen, are cessation of smoking, normalization of body weight, improvement of social class, decrease of stress levels, aerobic exercise, low-fat high-fibre diets, moderate alcohol intake and postmenopausal hormone replacement ${ }^{13,15,17,28}$.

\section{Conclusion}

The objective of this study was to describe the plasma fibrinogen levels of black Africans living in the Cape Peninsula. Relatively high levels were observed, tending to cluster with other, including diet-related, risk factors of CHD. It seems that the lower LDL levels and higher HDL total cholesterol ratio in this population, protect them against the noxious effect of fibrinogen as a risk factor of $\mathrm{CHD}$, since mortality rates from this disease are still low. However, it is suggested that the high fibrinogen levels may contribute to the excess mortality from stroke in this population. It is recommended that this aspect of fibrinogen as well as the association with iron status, should be further examined in epidemiological and clinical studies, and that measures to reduce fibrinogen levels which will also reduce other risk factors for chronic diseases should be promoted in this population.

\section{References}

1 Steyn K. A policy proposal to manage chronic diseases of lifestyle in South Africa. S. Afr. Med. J. 1992; 82: 220-1.

2 Popkin BM. The nutrition transition in low-income countries: an emerging crisis. Nutr. Rev. 1994; 52: 285-98.

3 Wilhelmsen L, Svärdsudd K, Korsan-Bengsten K, Larsson B. Fibrinogen as a risk factor for stroke and myocardial infarction. N. Engl. J. Med. 1984; 311: 5001-505.

4 Meade TW, Brozovic M, Charkrabarti RR, et al. Haemostatic function and ischaemic heart disease: principal results of the Northwick Park Heart Study. Lancet 1986; ii: 533-7.

5 Kannel WB, Wolf PA, Castelli WP, D'Agostino RB. Fibrinogen and risk of cardiovascular disease. J. Am. Med. Assoc. 1987; 258: $1183-6$.

6 Yarnell IWG, Fehilly AM, Milbank J, Kubicki AJ, Eastham R, Haynes TM. Determinants of plasma lipoproteins and coagulation factors in men from Caerphilly, South Wales. J. Epidemiol. Comm. Health. 1983; 37: 137-40.

7 Assman G, Schulte $H$. Results and conclusions of the prospective cardiovascular Münster (PROCAM) Study. In: Asmann G, ed. Lipid Metabolism Disorders and Comnary Hean Disease. Munich: MMV Medizin Verlag, 1993: 19-67.
8 Folsom AR, Wu KK, Conlan MG. Fibrinogen and cardiovascular risk in the atherosclerosis risk in communities (ARIC) study. In: Ernst E, Koenig W, Lowe GDO, Meade TW, eds. Fibrinogen: a 'New' Cardiovascular Risk Factor. Vienna: Blackwell-MZV, 1992: 124-9.

9 Erikson H, Wilhelmsen L, Welin L, Larsson B, Svärdsudd, Tibblin G. 21-year follow-up of CVD and total mortality among men born in 1913. In: Ernst E, Koenig W, Lowe GDO, Meade TW, eds. Fibrinogen: a 'New' Cardiovascular Risk Factor. Vienna: Blackwell-MZV, 1992: 115-19.

10 Tarallo P, Henny J, Gueguen R, Siest G. Reference limits of plasma fibrinogen. Eur. J. Clin. Chem. Clin. Biochem. 1992; 30: 745-51.

11 Folsom AR, Wu KK, Davis CE, Conlan MG, Sorlie PD, Szklo M. Population correlates of plasma fibrinogen and factor VII, putative cardiovascular risk factors. Atberosclerosis 1991; 91 : 191-205.

12 Lee AJ, Smith WCS, Lowe GDO, Tunstall-Pedoe H. Plasma fibrinogen and coronary risk factors: the Scoltish Heart Health Study. J. Clin. Epidemiol. 1990; 43: 913-19.

13 Cook NS, Ubben D. Fibrinogen as a major risk factor in cardiovascular disease. Trends Pharm. Sci. 1990; 11 : 444-51.

14 Humphries SE, Cook M, Dubowitz M, Stirling Y, Meade TW Role of genetic variation at the fibrinogen locus in determination of plasma fibrinogen. Lancet 1987 ; $\mathbf{i}$ : 1452-55

15 Ernst $E$. The role of fibrinogen as a cardiovascular risk factor. Atherosclerosis 1993; 100: 1-12.

16 Iso $\mathrm{H}$, Folsom AR, Sato $\mathrm{S}$, et al. Plasma fibrinogen and its correlates in Japanese and US population samples. Arterioscl. Thromb. 1993; 13: 783-90.

17 Venter CS, vorster HH, Silvis A, Mia F, Seftel HC. Determinants of plasma fibrinogen levels in South African communites. In: Ernst E, Koenig W, Low CDO, Meade TW, eds. Fibrinogen: a 'New' Cardiotacular Risk Factor. Vienna: Blackwell-MZV, 1992: 166-71.

18 Steyn K, Fourie J, eds. BRISK Study Methodolog. Coronary, Heart Disease Risk Factor Study in the African Population of the Cape Peninsula. Technical report no. I. Medical Research Council, Parow, 1991: 1-44.

19 Steyn K, Jooste PL, Bourne L, et al. Risk factors for coronary heart disease in the black population of the Cape Peninsula. S. Afr. Med. J. 1991; 79: 480-5.

20 Osterud B. How to measure factor VII and factor VII activation. Haemostasis $1983 ; 13: 161-8$.

21 Stat Soft Incorporated. Complete Statistical System (CCS). Stat Soft Inc. 1991, Tulsa, OK 74104.

22 Møller L, Kristensen TS. Plasma fibrinogen and ischemic heart disease risk factors. Arterioscler. Thromb. 1991; 11: 344-50.

23 Balleisen L, Bailey J, Epping PH, Schulte $H$, Van de Lon J. Epidemiological study on factor VII, factor VII and fibrinogen in an industrial population I. Thromb. Hemost. 1985; 54: 475 .

24 Farinaro E. Prevention of coronary heart disease: scientific background and new clinical guidelines. In: Asmann G, ed. Lipid Metabolism Disorders and Coronary Heart Disease. Munich: MMV Medizin Verlag, 1993: 69-139.

25 Vorster $\mathrm{HH}$, Venter CS. Fibrinogen as risk factor for coronary heart disease. Cardiovasc. J. S. Afr. 1994; 5: 117-24.

26 Kannel WB. CHD risk factors: a Framingham Study update. Hosp. Pract. 1990; 25: 119-27.

27 Luria MH, Erel J, Sapoznikov D, Gotsman MS. Cardiovascular risk factor clustering and ratio of total cholesterol to highdensity lipoprotein cholesterol in angiographically documented coronary antery disease. Am. J. Cardiol. 1991; 67: 131-6.

28 Ernst $\mathrm{E}$. Oral contraceptives, fibrinogen and cardiovascular risk. Atberosclerosis 1992; 93: 1-5.

29 Walker ARP, Adam A, Kustner HGV. Changes in total death rate and in ischaemic heart disease death rate in interethnic South African populations. S. Afr. Med. J. 1993; 83: 602-5. 
30 Sherman AJ. Coronary heart disease in black Americans; suggestions for research on psychosocial factors. Am. Heart J. 1984: 3: 833-8.

31 Vermaak WJH, Ubbink JB, Delport R, Becker PJ, Bissbort SH, Ungerer JPJ. Ethnic immunity to coronary heart disease? Atherosclerosis 1991; 89: 155-62.

32 Franz RC, Meiring JL, Coetzee WJC. Ethnic differences in the haemostatic, fibrinolytic and lipographic patterns. S. Afr. J. Surg. 1980; 18: 58-9.

33 Jerling JC, Vorster HH, Oosthuzen W, Silvis N, Venter CS. Differences in plasminogen activator inhibitor I activity between blacks and whites may be diet related. Haemostasis 1993: 24: 364-8

34 Wyndham CH. Mortality from cardiovascular diseases in the various population groups in the Republic of South Africa. S. Afr. Med. J. 1979; 56: 1023-30.

35 Joubert J. The MEDUNSA Stroke Data Bank. An analysis of 304 patients seen between 1986 and 1987. S. Afr. Med. J 1991; 80: $567-70$.

36 Broderick JP, Brott T, Tomsick T, Huster G, Miller R. The risk of subarachnoid and intracerebral hemorrhages in blacks as compared with whites. N. Engl. I. Med. 1992; 326: 733-6.
37 Kittner SJ, White LR, Losonczy KG, Wolf PA, Hebel JR Black-white differences in stroke incidence in a national sample. J. Am. Med. Assoc. 1990; 264: 1267-70.

38 Gaines KJ, Chesney C, Van der Zwaag R, Cape C. Racial differences in coagulation studies in stroke. Neurol. Res 1992; 14: 103-8.

39 Carter LR, Walton SE, Knowles MK, Wing S, Tyroler HA. Social inequality of stroke mortality among US black populations, 1968 to 1987. Ethn. Dis. 1992; 2: 343-51.

40 Casper M, Wing S, Strogatz D. Variation in the magnitude of black-white differences in stroke mortality by community occupational structure. J. Epidemiol. Comm. Healtb 1991; 45: 302-6.

41 Markowe HLJ, Marmot MG, Shipley MJ, et al. Fibrinogen: a possible link between social class and coronary heart disease. Br. Med. J. 1985; 291 : 1312-14.

42 Netterstrøm B, Søndergård K, Damsgaard MT, Olsen O, Sjøl A. Job strain and cardiovascular risk factors; a cross sectional study of employed Danish men and women. Br.J. Ind. Med. 1991; 48: 584-689. 